reproduction has taken place in their ancestry being at the same time reduced to a minimum.

On the contrary, we nust expect that a much smaller number of ancestors lies between the lower-developed groups and the common parent form, that a-sexual reprociucion has here more repeatedly occurred, and that finally, Darwin's and Huxiey's explanation, which we have above alluded to, of the non-cccurs ence of further modifications, may here have been realised to a greater extent.

Keefing in view the combined action of both these principles, we no longer worder that even in the present day living representatives are found of genera which were already present in the Silurian epoch, nor that the simplest organised beings have continued to exist in that plimitive form.

They are for the greater part the younger scns, and being condemned to a sloner rate of development, they could not keep apace of their elder brothers. The latter, $\mathrm{n}$ hich bave so much oftener passed through the improving crucit le of sexual reproduction, are indebted to that cause for having become the parent stock out of which the bigher and highest-developed animal and vegetable forms, now surrcunding us, have gradually sprung.

\section{THE ETHER AND ITS FUNCTIONS ${ }^{1}$}

I HOPE that no cne bas been misled by an error in the printing of the title of this lecture, viz. the omission of the definite article before the word ether, into : uppesing tlat $I$ am going to discourse on chemistry and the latest anæsihetic; you will have understood, I hope, that "ether" nieant the ether, and that the ether is the hypothetical medium which is supposed to fill otherwise empty space.

The idea of an ether is by no means a rew one. As soon as a notion of the enormous extent of space had been grasped, ly means of astronomical discoveries, the question presented it elf to men's minds, what was in this space? vas it full, or was it empty? and the question was differently answered by different metaphysicians. Sore felt that a vacuum was so abborrent a thing that it could not by any possibility exist anyw here, tut that nature would not be sati:fied unless space were perfectly full. Others, again, felt that cmpty space cculd hardly exist, that it would shrink up to nothing like a priched bladder unless it were kept distended by : omethin g material. In other w ords, they made matter the condition of extension. On the other hand, it was conterded that however objectionable the idea of empty space might be, yet emptiness was a necessity in order that bodies might have room to move; that, in fact, if all sl ace were perfectly full of matter everything would be jammed together, and nothing like free attraction or fiee motion of bcdies round one another could go on.

And indeed there are nol wanting philosophers at the present day who still believe something of this same lind, who are satisfied to think of matter as consisting of detached small particles acting on one another with forces varying as some inverse power of the distance, and who, if they can account for a phenomenon by an action exerted acro:s empty space, are content to go no further, nor seek the cause and nature of the action nore closely. ${ }^{2}$

Now metaphysical arguments, in so far as th ay have any weight or validity whatever, are unconscic us appeals to experience ; a person endcavours to find ont whetler a certain condition of things is by him conceivable, and if it is not conceivable he has some primâ facie grcund for asterting that it probably does not exist. I say he has some ground, Lut whether it be much or little depends fartly on the nature of the thing thought of, whether it ke fairly simple or highly complex, and partly on the range of the man's on n nental development, whether his experience be wide or narrow.

If a highly-developed mind, or set of minds, find a dcctrine about some comparatively sin ple and fundames tal matter absolutely unthinkable, it is an evidence, and it is accepted as good evidence, that the unthinkable state of things is one that has no existence ; the argument being that if it did exist, either it or something not wholly unlike it wonld have come within the range of experience. We have no fur ther evidence than this for the statement that two straight lines cannot inclose a space, or that the three angles of a triangle are equal to two right angles.

I A lecture by Prof. Oliver Lcdge at the Lcnden Institution, on $\Gamma$ ecember 28, $x 882$.

Janu illustration of this statement an artic.e has since appeared in the
Nevertheles there is nothing final about sucl an angument; all that the inccinceivability of a thing really prcves, or can prove, is that nothirg like it has ever ccme within the thinler's experience; and this proves nothing as to the rcality $(r$ nen-reality of the thing, unless his experierce of the same lind of ihings bas been so extersive as to male it reasonal ly prol at le that if such a thing had existed it would not have bcen so completely overlooked.

The experience of a child or a dog, on ordinary scientific phenomena, therefore, is worth next to nothing; and as the experience of a dog is to oidinary science, so is the experience of the human race to some higher henon ena, of $w$ hich they at present know nothing, and against the existence of which it is perfectly futile and presumptucus to bring forward arouments about their being inconceivable, as if they were likely to be anything else.

Now if there is one thing with which the human race has been more conversant from time immemorial than another, and concerning which more experience has been unconscicusly accumulated than about almost anything else that can be mentioned, it is the action of one body on another; the exertion of force by one body upon another, the transfer of motion and energy from one body to another; any lind of effect, no matter what, which can be prcduced in one body by means of another, whether the bodies be anir ate or inanimate. The action of a man in felling a tree, in thrusting a spear, in drawing a bow ; the action of the bow again on the arrow, of powder on a bullet, of a horse on a cart; and again, the action of the earth on the mcon, or of a magnet cn iron. Every activity of every kird that we are conscic us of may be taken as an illustration of the action of one bedy on another.

Now I wish to appeal to this mass of experience, and to ask, is not the direct action of one boojy on another across $\epsilon$ mpty space, atd $\mathrm{x}$ ith no means of communication whatever, is not this absolutely unthinkable? We $\mathrm{n}$ ust not answer the que tion offhand, l ut must give it due consideration, and we shall find, I think, that wherever one body acts c $n$ another by obvious contact, we are satisfied and have a feeling that the chencmenon is simple and intelligible; but that whenever one bcdy apf arently acts on another at a distance, we are irresistibly impelled to look for the connecting medium.

If a marionette dances in ol edience to a prompting hand above it, any intelligent child would feel $f \circ r$ the wire, and if no wire or anything corresconding to it were discovered, wculd feel that there was scmething uncanny and magical about the whole thing. Ancient attempts at magic were indecd attempts to obtain results withcut the trouble of properly causing them, to tuild palaces by rubbing rings or lanterns, to remove mountains by $a \mathrm{w}$ is $h$ instead of $w$ ith the spade and piclaxe, and generally to act on bodies without any real means of comn unication; and rodern disbelief in magic is simply a statement of the conviction of mankind that all attempts in this direction have turned out failures, and that action at a distance is impossible.

If a man explained the action of a horse or a cart by saying that there was an attraction between $t h \mathrm{~m}$ varyir $\mathrm{g}$ as some high direct pcwer of the distance, he would not be saying other than the truth - the facts may be so expre sed-l ut be would ke felt to te giving a wretchedly leme explanation, and ary one who simply pointed out the traces wculd be going much more to the root of the matter. Similarly with the attraction of a magnet for another magnetic pole. To say that there is an altraction as the inverse cube of the distance between them is true, 1 ut it is not the whole truth; ard we should be oblised to any cne who will point cut the traces, fcr traces we feel sure there are. If any one tries to picture clearly to himself the action of ore body on another without any medium of ccmmunication whatever, he must fail. A medium is instinctively looked for in most cases, and if not in all, as in falling weights or in magnetic attraction, it is only because custom has made us stupidly callous to the real nature of these forces.

Wh $\mathrm{n}$ v e see a vehicle bowling down-hill without any visible profelling force we cught to regard it with the same mixture of curicsity and wonder as the Chin: man felt when he saw for the first time in the streets of Philadelphia a tram-car driven by a rcpe buricd in a pipe underground. The attichment to these cars cones through a narrc w slit in the pipe, and is quite unobthusive. After regarding the car with open-monthed astonichnient for some time, the Chinaman made use of the following memorable exclamation, "No tu.hee-No pullee-Go Jike mad!" He was a philosopbic Chinaman. 
Renenber then that whenever we see a thing bein $z$ moved we mu t l ook for the rope; it may be vi ible or it may be invısible, bu: unless there is either "pushee" or "pullee" there c an be $n$, act on. And if you further consider a pull it revolves itself into a push; to pull a thin $y$ tow ards you, you have to put your finger behin 1 it and push ; a horse is said to pull a cart, but he is really push$i$ ir at the collar; an engine pushes a truck by mexns of a hook ant eye; and so on. There is still the furthrr very important and difficult question $a$; to why the parts hang together, and why when you push one part the rest follows.

Cohesion is a very striking fact, and an explanation of it is mueh to be desire 1; I shall have a little $m$ re to say ab sut it later, bat at present we have nothing more than an indication of the direction in which an explanation seems poisible. We cunnot speak distinctly about those actions which are as yet mysterious to $\mathrm{u}$; , but concerning those which are co nparatively simple and intelligible we mzy make this general statement:The only way of acting on a body directly is to pu ih it behind.

There muit be coltact between bodies before they can directly aci on each other; and if they are not in contact with each other and yet act, they mu it both be in $\mathrm{c}$ nntact with some third body which is the medium of communication, the rope.

Consider now for an instant the most complex case, the action of one animate boly on an ther not touching it. To call the attention of a dog, for instance, there are several methods: one plan is to prod him with a stick, an ther is to heave a stone at him, a third is to whistle or call, while a fourth is to beskon him by gesture, or, what is essentially the same proces i, $t$, flash sunlight into his eye with a mirror. In the first two of thes methods the media of commanication are perfectly obvious-the stick and the stone-in the third, the whistle, the medium is not so obviou;, and this case mi rht easily seem to a savare like action at a distance, but we know of courie that it is the air, and that if the air between be taken away, all com nunication $b_{j}$ sound is interrupted. But the f urth or optical method is not so interrupted; the dog can see through a vacuum perfectly well, though he carnot hear through it; but what the mediu n now i which conveys the impression is not so well known. The sun's light is conveyed to the earth by such a medium as this acrois the emptiness of planetary space. The only remaining typical plans of acting on the dor would bs either by electric or may nstic attractio $1 ;$, or by mes neris n, and I would hiv s you seek for the medium which conveys these impresions with just as great a certainty that there is one a; in any of the other cases.

Lexving the ie more mysterious and subtle mode; of comnunication, let us return to the two most simple ones, viz., the stick and the stone. These two are representative of the only possible fundamental moles of communication between distant bolies, f)r one is compelled to believe thit every more occult mole of action will ulti nately resolve itself into one or other of these two

The stick represe ts the methol of commuaication by continuous su'stance; the stone reprejents the connuaisation by actual transfer of matter, or, a; I shall call it, the projectile meth d. There are no other known methol; fo: one body to act on another than by these two -by continu sus meditum a id by projectile.

We know one clear an I well-established examsle of the pro jecile $m$ tho l, viz., the transmission of pres iure by gases. A gas con ists of particles perfectly independent of exch other, and the onl $y$ way in which they can ast on each othe: $i$; by blo vs. The pressu:e of the air is a bonbard nent of particles, and actions are trans nitted throurh gase; as through a $r o w$ of ivory balls. Sound i; propa ratel by each purticle receiving a knock a dd passing it on to the next, the final effest being mush the sam 2 as if the first struck particles had been shot off through the whole distance.

The explanition of the whole behavisur of gases in this manner is so si inple and satisfacto:y, an $t$ moresver is so certainly the true aec sunt of the matter, that we are naturally temptet to ask whether this projectile theory is not the key to the universe, and whether every kint of action whatever cannot be worked out o. this hypothesis of atoms blindly drivint about in al directions at perfect random and with complete in lependence of each other except when they c sllide. ${ }^{1}$ And accordingly we bave the corpuscu'ar the srie; of light and of gedvitation; both accsan for the respective phens.nena by a battering of particles. The corpuscular the ry of gravitatio 1 is, however, full of diffisultie; for it is not obvious accorling to it why the weirht of a plate is

r To this hyp thesis Mr. Tolver Preston has ald:essed him self with much ingenuity. the same when held ed reways a; when held broalside on, $i_{1}$ the stream of corpu cles; while it is surprising (as indeed it parhıps is on any hypothesis) that the weight of a body is the same in the solid, liquid, and gaseous states. It has been atte npted to explain cohesion aliso on the same hypothesis, but the diffi salt es, which were great enough before, are now enormous, and to me at any rate it seem; that it is only by violent straining a d by inprobable hypothese; that we can explain all the actions of the universe by a mere battery of particles.

Moresver, it is difficult to understand what the ato ns the nselve; can be like, or how they can strike and bound off one an ther without yielding to compression and then soringing out again like two ela tic ball; ; it is difficult to understand the elasticity of really ultimate hard particles. Ant if the atoms are not such hard particles, but are elastic and yielding, and bound from one another according to the same sort of law that ivo:y balls d, of what are they composed? We shall have to b grin all over agdin, an I explain the cohesion and elasticity of the parts of the atom.

The more we think over the matter, the more are we compelled to abandon mere impact as a complete explanation of action in general. But if this be so we are driven back upon the other hypothesis, the only other, viz. communication by continu $)$ i medium.

We must begin to imagine a continuous connecting mediun between the particle; - a su'stance in which they are imbedded, and which extends into all thair interstices, and cxtends with out break to the remstest linit; of space. Once grant this and difficulties be gin rapidly to disappear. There is now con in uous contact batween the particles of bodies, and if one is pushed the others naturally receive the motion. The atsins of gas are impinging as bəfore, but we have now a different idea of w'at impact me uns.

Gravitation is explainable by differences of pressure in the medium, caused by so:ne action batween it and matter not yet understood. Cohesion is explainable also probably in the same way.

Light consists of undulation or waves in the madium; while electricity is turning oxt quite possibly to bə an asp sct of a part 0 ? the very medium itself.

Tha mediun is now accepte 1 as a necessity by all modern physicists, for witaout it we are groping ix the dark, with it we feel we have a clue which, if followed up, may lead us into the innermost secrets of nature. It has as yet been followed up very partially, but I will try an $t$ in dicate the directions in which modern science is tending.

The name you chosse to give to the merlium i; a matter of very sinall importance, but "the Ether" is a; good a name for it as another.

As fa: as we know it appears to be a perfectly ho nozeneous incsupressib'e continuous body insapable of being resolved into si uple elements or atoms; it is, in fact, continuou;, $n$ t moleculat: There is no other boly of which we can say this, and hence the propertie; of ethei must be somewhat different fron thse of ordina:y matte: But there is little difficulty in piciuring a continusu; substanse to ourselves, inasmuch as the molecular and porou; nature oc o*di xary matter i; hy no wien evideat to the senses, but is an inferen se of some diff :uity.

Ether is often called a fluid, or a liquid, and a yain it has been called a sulid and has been likened to a jelly brcau e of its rigidity; but none of these numes are very much gosd; all these ace molecular groupings, and therefore not like ether; let ws think simply and solely of a continu u; frictionl sss metiun posiessing inertiz, and the vaguene is of the notion will bo nothing more than is propes in the present state of our knowledge.

We have now to try and realise the idea of a perfectly con tinuous, subtle, inc sap:e sisible substance pervading all sp rce a nd penetratin between the mo'ecules of all ordinary $m$ itter, which are inballed in it, ant conzect ad with one anther by its mean;. And we muit reg ird it as th 2 one universal medium by which all actions between bodies are carriel on. Thi i, tien, is its function - to act as the transmitter of motion and of e.tersy. First consiter the propagation of light.

Sound is propagated by direct excursion and impast of the atoms of ordina:y matter. Light is not so propagatel. How do we know this?

I. Because of spzed, $3 \times \mathrm{ro}^{10}$, which is greater than anything transmissible by ordinary matter.

2. Because of the kind of vibration, as revealed by the p'sens. mena of polarisation. 
The vibrations of light are not such as can be transmitted by a set of disconnected molecules; if by molecules at all, it must be by molecules connected into a solid, i.e. by a body with rigidity. Rigidity means active resistance to shearing stress, i.e. to alteration in shape ; it is also called elasticity of figure; it is by the possession of rigidity that a solid differs from a fluid. For a body to transmit vibrations at all it must possess inertia; transverse vibrations can only be transmitted by a body with rigidity. All matter possesses inertia, tut fluids only possess volume elasticity, and accordingly can only transmit longitudina vibrations. Light consists of transverse vibrations; air and water have no rigidity, yet they are transparent, i.e. transmit transverse vibrations; hence it must be the ether in ide them which really conveys the motion, and the ether must have properties which, if it were ordinary matter, we should style inertia and rigidity. No highly rarefied air will serve the purpose ; the ether must be a distinct body. Air exists indeed in planetary space even to infinity, but it is of almost infinitesimal density compared with the ether there. It is easy to calculate the density of the atmosphere at any height above the earth's surface, supposing other bodies absent.

The density of the air at a distance of $n$ earth radii from the centre of the earth is equal to a quarter the density here divided by $10^{350 \frac{n-1}{n}}$. the decimal point before the significant figures begin. The density of ether, on the other hand, has been calculated by Sir William Thomson from data furnished by Pouillet's experiments on the energy of sunlight, and from a justifiable guess as to the amplitude of a vibration, and it comes out about $10^{-18}$, a number with only 17 ciphers before the significant figures. 'In inter-planetary space, therefore, all the air that exists is utterly negligible; the density of the ether there, though small, is enormous by comparison.

Once given the density of the ether, its rigidity follows at once, because the ratio of the rigidity to the density is the square of the velocity of transverse wave propagation, viz. in the case of ether, $9 \times \mathbf{I O}^{20}$. The rigidity of ether comes out, therefore, to be about 9oo. The most rigid solid we know is steel, and compared with its rigidity, viz. $8 \times 10^{11}$, that of ether is insignificant. Neither steel nor glass, however, could transmit vibrations with anything like the speed of light, because of their great density. The rate at which transverse vibrations are propagated by crown glass is halt a million centimetres per second - a considerable speed, no doubt, but the ether inside the glass transmits them 40,000 times as quick, viz. at twenty thousand million centimetres per second.

The ether outside the glass can do still better than this, it comes up to thirty thousand million, and the question arises what is the matter with the ether inside the glass that it can only transmit undulations at two-thirds the normal speed. Is it denser than free ether, or is it less rigid? Well, it is not easy to say; but the fact is certain that ether is somehow affected by the immediate neighbourhood of gross matter, and it appears to be concentrated inside it to an extent depending on the density of the matter. Fresnel's hypothesis is that the ether is really denser inside gross matter, that there is a sort of attraction between ether and the molecules of matter which results in an agglomeration or binding of some ether round each atom, and that this additional or bound ether belongs to the matter, and travels about with it. The rigiaity of the bound ether Fresnel supposes to be the same as that of the free.

If anything like this can be imagined, a measure of the density of the bound ether is easily given. For the inverse velocity-ratio is called $\mu$ (the index of refraction), and the density is inversely as the square of the velocity, hence the density-measure is $\mu^{2}$. The density of ether in free space being called $I$, that inside matter has a density $\mu^{2}$, and the density of the bound portion of this is $\mu^{2}-\mathrm{I}$.

This may all sound very fanciful, but something like it is sober truth; not as it is here stated very likely, but the fact that $\left(\mathbf{I}-\frac{\mathbf{I}}{\mu^{2}}\right)$ th of the whole ether inside matter is bound to it and travels with it, while the remaining $\frac{I}{\mu}$ th is free and blows freely through the pores, is fairly well established and confirmed by direct experiment.

(To be continued.)

\section{UNIVERSITY AND EDUCATIUNAL INTELLIGENCE}

CAMBRIDGE.-The following further announcements of lectures have been made :-

Prof. Humphry, Circulatory and Respiratory Systems, Jan. 25; senior class, Jan. 29; Demonstrations by the Demonstrator for Natural Science Tripos, Jan. 26; Osteology, for beginners, Jan. I 7 ; Demonstrations for second year students, Jan. 18; Mr. McAlister will give six lectures later in the term, on the Mechanism of the Human Skeleton. Dr. Michael Foster's course of Elementary Physiology, Jan. 23; Mr. Lea, Chemical Physiology, Jan. 24 ; Dr. Vines, Anatomy of Plants, advanced, with practical work, Jan. 24 (Christ's College); General Elementary course, New Museums, Jan. 23, to extend over two terms, and be illustrated by demonstrations. A class for the practical study of systenatic botany, Mr. T. H. Corry, assistant curator of the Herbarium, will be formed. Dr. Hicks will lecture on the Morphology of Flowering Plants, with especial reference to classification, including floral diagrams, in the Hall of Sidney College, beginning Jan. 26; Mr. Glazebrook, advanced Demonstrations in Electricity and Magnetism, Caven dish Laboratory, Jan, 24; Mr. Shaw, Demonstrations in Mechanics and Heat, Jan. 23; if more students attend than can be accommodated in the laboratory at one time, the course will be repeated on the same days. Mr. Trotter, Trinity College, Physical Optics, Jan. 25. Mr. Pattison Muir, Nonmetallic Elements, Elementary, Jan. 22, Caius College Labora. tory; General Principles of Chemistry, Advanced, Jan. 23 Mr. Solly will give Demonstrations on Minerals in the Lecture Room of the Mineralogical Museum, first lecture, Jan. 22. Prof. Stuart, Jacksonian Lecture Room, Theory of Structures, Jan. 30 the Demonstrator of Mechanism, Mathematics required for Engineering, Jan. 29.

Christ's College Open Scholarships, Natural Science; E. L. Sortain, Bath College, 3ol.; 3rd year, J. C. Bose, 3ol.; Caius College, Natural Science, Edgworth, Clifton College, 4ol.

Mr. MARSHALL WARD is giving a course of free public lectures at Owens College, on the Nutrition of Plants.

\section{SCIENTIFIC SERIALS}

Fournal of the Franklin Institute, January.-Electric lighting in mills, by C. J. H. Woodbury.-Bricks and brick-making machinery, by C. Chambers, Jun.-Experiential principles of controlled combustion, by E. J. Mallett, Jun.-Olsen's testing machines.

Archives des Sciences Physiques et Naturelles, December 15 , 1882. - Meteorological résumé of the year 1881 for Geneva and the great St. Bernard, by A. Kammermann.-Observations on cometary refraction, by W. Meyer.-Development of the vegetable kingdom in different regions since the tertiary epoch, according to Dr. Engler's work, by A. de Candolle.-Yeriodical movements of the air indicated by spirit levels, by $\mathrm{Ph}$. Plantamour.-On the same, by C. von Orff.

\section{SOCIETIES AND ACADEMIES LONDON}

Chemical Society, January 18.-Dr. Gilbert, president, in the chair.-It was announced that a ballot for the election of fellows wouid be held at the next meeting, February $1 .-T h e$ following lapers were read:-The fluorine compounds of uranium, by A. Smithells. The author has investigated the action of aqueous hydrofluoric acid upon the green uranoso-uranic oxide. He finds that a voluminous green powder, uranium tetrafluoride, is left, and that a yellow solution is formed which contains uranium oxyfluoride. The author confirms the results previously obtained by Bolton, and proves those obtained by Ditte to be erroneous.- On a new method of estimating the halogens in volatile organic compounds, by R. T. Plimpton and $\mathrm{E}$. E. Graves. The authors burn the vapour of the compound in a glass Bunsen burner, the products of the combustion are aspirated through caustic soda solution, which is heated with sulphurous acid and the halogen precipitated by silver nitrate, \&c., in the usual way. Good results were obtained with various liquids from ethyl bromide boiling at $39^{\circ}$ to acetylene bromiodide boiling at $150^{\circ}$.- On a modified Liebig's condenser, by W. A. Shenstone. The author has slightly modified a vertical con 